\title{
Outcomes of Patients Who Have Undergone AV Shunt Procedure at Dr. Zainoel Abidin General Hospital in Banda Aceh
}

\author{
Khalikul Razi ${ }^{1}$, Yopie Afriandi Habibie ${ }^{2}, Z_{\text {Zulfan }}^{3}$, Rovy Pratama \\ ${ }^{1,2}$ Departement of Surgery, Medical School, Universitas Syiah Kuala, Dr. Zainoel Abidin Public Hospital, \\ Banda Aceh, Indonesia \\ ${ }^{3}$ Faculty of Medicine, Universitas Syiah Kuala, Banda Aceh, Indonesia \\ ${ }^{4}$ Unit of Medical Research, Faculty of Medicine, Universitas Syiah Kuala, Banda Aceh, Indonesia \\ khalikulrazi@unsyiah.ac.id
}

\begin{abstract}
In recent decades, kidney disease has been documented as a global public health problem. The current challenge is about improving the treatment of chronic kidney disease (CKD) patients in order to provide a longer life expectancy for them. In hemodialysis, there has been a considerable development in finding access to the vascular system, one of which developments was the creation of arteriovenous access by Cimino and Brescia (called an AV shunt). Research on the AV shunt is still limited, so the researchers are interested in conducting this descriptive epidemiological survey study on the profile of patients undergoing AV shunt procedures at Dr. Zainoel Abidin General Hospital in Banda Aceh in 2017. Data were obtained retrospectively from the medical records of the Central Surgery Installation Department of Dr.Zainoel Abidin General Hospital in Banda Aceh, and there were 105 patients have undergone AV shunt, 72 men $(68.6 \%)$ and 33 women (31.4\%). The frequency based on the age was the risking age about 45-54 years as many as 30 people (28.6\%). Based on the outcomes obtained 95 people (90.48\%) who have used the AV shunt for hemodialysis access, consisting of 66 men (62.86\%) and 29 women (27.62). Based on the duration of use, AV Shunt is mostly used for 1 year with the number of 48 patients (50.52\%) in the proportion of men and women were $38.95 \%$ and $11.57 \%$. With an average duration of use of AV Shunt 2,6 years. From the results of this study, we conclude that the result was obtained that the highest cases in patients who have undergone AV Shunt is man as much as 68.6\%. Furthermore, Pertaining to this study, it was obtained that the majority of age who undergo Av shunt is 45-54 years. In addition, the result of this study showed that the success rate of surgery AV shunt in Dr. Zainoel Abidin General Hospital in Banda Aceh was high. It is about 90, 48\% with an average duration use of Av shunt is 2.6 years.
\end{abstract}

Keywords: AV shunt; outcomes of patients; chronic kidney disease

\section{Introduction}

Kidney disease has been experienced by humans since ancient times. Interest in the medical field on the detection and treatment of kidney disease can be traced from ancient times, but the efforts made are still fragmented and almost entirely focused on the manifestation of symptoms of the disease alone. However, in recent decades, kidney disease has been documented as a global public health problem (Scholz H. AV Fistulas, 2015).

Every year chronic kidney disease (CKD) is experienced by 1 in 10 adults (10\%) worldwide or around 500.000 people each year. Data on food intake was obtained using a food recall form which was asked of respondents accompanied by their parents (Simorangkir, 2020). Only a combination of foods from different groups can ensure an optimal dietary balance (Skerrett \& Willett, in Lazaniriana, 2020). However, 
concret data regarding the actual incidence and prevalence of CKD are hampered by the lack of both proper recording and national kidney registers. The incidence and prevalence of CKD is greater in developing countries (Cheungpasitporn W, 2015).

A Dialysis was used as an exploratory effort to sustain the lives of kidney failure patients in the later years of the Second World War. Dialysis developed in the 1970s and became a life-saving therapy for patients with CKD which progressed to kidney failure and required the need for kidney replacement therapy (KRT) by dialysis (Turner J.M., 2012).

The current challenge is how the treatment of CKD patients will provide a longer life expectancy. Thus, in-depth knowledge is needed in order to obtain the best and longestlasting solutions to maintain existing hemodialysis access or create a new hemodialysis access (Arici M., 2014).

\section{Review of Literatures}

Vascular access to hemodialysis is strongly related to patient survival. In addition, greater life expectancy, dialysis efficiency, and quality of life for patients are also highly dependent on vascular access. In hemodialysis, there have been considerable developments in vascular access, one of which is the creation of arteriovenous access by Cimino and Brescia (Turner J.M., 2012).

There are several options for connecting CKD patients to hemodialysis machines. One of them is arteriovenous access which is a type of permanent vascular access. Vascular access that creates a functional portal to the patient's circulatory system is very important in providing adequate hemodialysis therapy. The ideal hemodialysis access should fulfill three criteria: first, to have a lifetime of use; second, to provide sufficient blood flow rates to reach the dialysis dose; and third, have a low rate of related complications. There is no perfect form of hemodialysis access to satisfy all three criteria, but an $\mathrm{AV}$ shunt is one of the best methods that has been developed thus far (Eknoyan G, 2012).

Research on AV shunt is still limited, so the researchers are interested in conducting a descriptive epidemiological survey study on the midterm follow-up meeting of patients who have undergone an AV shunt procedure at Dr. Zainoel Abidin General Hospital in Banda Aceh.

\section{Research Method}

This study is a descriptive study with a retrospective approach. This study uses a cross-sectional survey design meaning data were collected at one time (point time approach). The purpose of this study is to determine the outcomes of patients who have undergone an AV shunt procedure at Dr. Zainoel Abidin General Hospital in Banda Aceh. This study was conducted in the Hemodialysis Installation Room, Dr. Zainoel Abidin General Hospital in Banda Aceh and the time of the study was April 2018. The sample in this study was all patients who underwent hemodialysis through an AV shunt at Dr. Zainoel Abidin General Hospital in Banda Aceh, and who met the inclusion and exclusion criteria. The sampling technique used is the total population method, which is a sampling method which is done by taking the entire number of samples in a population that meets the inclusion and exclusion criteria as follows:

Inclusion Criteria

1. Hemodialysis patients who have undergone an AV shunt procedure

2. Patients of all ages 


\section{Results and Discussion}

\subsection{Results}

Data collection in this study was carried out at Dr. Zainoel Abidin General Hospital in Banda Aceh with all data retrieved from secondary data derived from medical records and registration records of the Hemodialysis Installation Room. Data were collected about the age, sex, and outcome variables of patients after an AV shunt was performed. These data were collected for 105 patients.

Table 1. Frequency Distribution Types Of Sex Patients Who Have Been Examining Av-Shunt Action at Dr. Zainoel Abidin General Hospital in Banda Aceh

\begin{tabular}{|l|c|c|}
\hline \multicolumn{1}{|c|}{ Sex } & $\begin{array}{c}\text { Frequency } \\
(\mathbf{n})\end{array}$ & $\begin{array}{c}\text { Percentage } \\
(\boldsymbol{\%})\end{array}$ \\
\hline Men & 72 & 68.6 \\
\hline Women & 33 & 31.4 \\
\hline Total & $\mathbf{1 0 5}$ & $\mathbf{1 0 0}$ \\
\hline
\end{tabular}

Based on the information in Table 1, it was found that the AV shunt procedure was more often performed on men, 72 cases $(68.6 \%)$ with a male-to-female ratio of around 2:1.

Table 2. Frequency Distribution Based on Age of Patients Received Av-Shunt Procedure at Dr. Zainoel Abidin General Hospital in Banda Aceh

\begin{tabular}{|l|c|c|c|}
\hline \multirow{2}{*}{$\begin{array}{c}\text { Ages (in } \\
\text { years) }\end{array}$} & \multicolumn{2}{|c|}{ Sex } & \multirow{2}{*}{$\begin{array}{c}\text { Tot } \\
\text { al }\end{array}$} \\
\cline { 2 - 4 } & Men & Women & (11 \\
\hline$<35$ & 11 & 4 & 15 \\
\cline { 2 - 4 } $35-44$ & 14 & 5 & 19 \\
$45-54$ & 18 & 12 & 30 \\
\cline { 2 - 4 } $55-64$ & 16 & 9 & 25 \\
$65-74$ & 13 & 2 & 15 \\
$>75$ & - & 1 & 1 \\
\hline Total & 72 & 33 & 105 \\
\hline
\end{tabular}

Based on the information in Table 2, the age range of 45-54 years was the group of patients which received the most AV shunt procedures, at 30 cases (28.6\%) with a proportion of $17.1 \%$ in men and $11.5 \%$ in women.

Table 3. Outcomes of Patients who Received an Av Shunt Procedure at Dr. Zainoel

Abidin General Hospital in Banda Aceh

\begin{tabular}{|l|l|c|c|c|}
\hline \multicolumn{2}{|l|}{ Outcome } & Men & Women & Total \\
\hline Succeeded & $\mathrm{N}$ & 66 & 29 & 95 \\
\cline { 2 - 5 } & $\%$ & 62.86 & 27.62 & 90.48 \\
\hline \multirow{3}{*}{ Failed } & $\mathrm{N}$ & 6 & 4 & 10 \\
\cline { 2 - 5 } & $\%$ & 5.71 & 3.81 & 9.52 \\
\hline Total & $\mathrm{N}$ & 72 & 33 & 105 \\
\cline { 2 - 5 } & $\%$ & 67.56 & 32.44 & 100 \\
\cline { 2 - 5 } & & & &
\end{tabular}


In Table 3, it appears that there are 95 cases (90.48\%) of patients who underwent an AV shunt procedure for hemodialysis access with the proportion of men and women being $62.86 \%$ and $27.62 \%$, respectively.

Table 4. Patients' Duration of Use of AV Shunt

\begin{tabular}{|l|l|c|c|c|}
\hline \multicolumn{2}{|l|}{$\begin{array}{l}\text { Duration } \\
\text { (in years) }\end{array}$} & Men & Women & \multicolumn{1}{l|}{ Tota } \\
\hline 0-1 & N & 37 & 11 & 48 \\
\cline { 2 - 5 } & $\%$ & 38.95 & 11.57 & 50.52 \\
\hline $\mathbf{1}-\mathbf{2}$ & $\mathrm{N}$ & 6 & 2 & 8 \\
\cline { 2 - 5 } & $\%$ & 6.31 & 2.11 & 8.42 \\
\hline $\mathbf{2 - 3}$ & $\mathrm{N}$ & 6 & 6 & 12 \\
\cline { 2 - 5 } & $\%$ & 6.31 & 6.31 & 12.62 \\
\hline $\mathbf{3 - 4}$ & $\mathrm{N}$ & 6 & 2 & 8 \\
\cline { 2 - 5 } & $\%$ & 6.31 & 2.11 & 8.42 \\
\hline \multirow{3}{*}{$\mathbf{4}-\mathbf{5}$} & $\mathrm{N}$ & 7 & 2 & 9 \\
\cline { 2 - 5 } & $\%$ & 7.37 & 2.11 & 9.48 \\
\hline$>5$ & $\mathrm{~N}$ & 7 & 3 & 10 \\
\cline { 2 - 5 } & $\%$ & 7.37 & 3.17 & 10.54 \\
\hline Total & $\mathrm{N}$ & 69 & 26 & 95 \\
\cline { 2 - 5 } & $\%$ & 72.62 & 27.38 & 100 \\
\hline
\end{tabular}

Based on Table 4, it appears that of the 95 patients used an AV shunt for hemodialysis, the maximum duration of AV shunt use was 1 year with 48 patients $(50.52 \%)$ with the proportion of men and women being $38.95 \%$ and $11.57 \%$, respectively. The average duration of use was 2.6 years.

\subsection{Discussion}

This research was carried out at Dr. Zainoel Abidin General Hospital in Banda Aceh. This study aims to determine the outcomes of patients who have undergone the AV shunt procedure. Samples were taken from the medical records of patients undergoing hemodialysis at the hemodialysis installation. In this study, 105 samples were found that met the inclusion criteria. Based on gender, more male patients were found compared with female patients, namely 72 cases (68.6\%) and 33 cases (31.4\%), respectively. This is consistent with the study conducted by Lilly et al. (Lilly MP, 2012) which found that the proportion of patients undergoing AV shunt was higher in men compared to women, namely $64.4 \%$ and $35.6 \%$. This can occur because, epidemiologically, men suffer higher rates of CKD compared to women. These epidemiological data are closely related to the lifestyle of men who are more often exposed to risk factors for CKD compared to women.

In this study, it was found that the highest number of cases which used an AV shunt was in the age range of 45-54 years, with 30 cases $(28.6 \%)$. The results of this study are 
also in accordance with research conducted by Lilly et al. in which it was found that the highest proportion of patients who underwent the AV shunt procedure were patients under 65 years old $(21.68 \%)$, and this was from about 45,547 cases studied. In Fokou et al. (2012), the average age of patients was 43.5 years (of 518 cases studied), which is lower when compared to the findings of Lilly et al. (2012).

In this study, all samples were given an AV shunt after they were diagnosed with CKD Based on the outcomes of patients who used an AV shunt procedure, there were 95 patients $(90.48 \%)$ had used an AV shunt for hemodialys is access.

The most common duration of use of AV shunt patients was 1 year, with 48 patients $(50.52 \%)$ with the proportion of men and women being $38.95 \%$ and $11.57 \%$. The average duration of use of an AV shunt was 2.6 years.

\section{Conclusion}

In this study, we report the outcomes of patients who underwent the AV shunt procedure at Dr. Zainoel Abidin General Hospital in Banda Aceh. From the results of this study, we conclude that the outcomes of patients who have had AV shunt measures performed at Dr. Zainoel Abidin General Hospital in Banda Aceh are good. Patients who have undergone the AV shunt procedure have been able to use their AV shunt for hemodialysis access for an average duration 2.6 years.

\section{References}

Arici M. (2014). Management of Chronic Kidney Disease: A Clinician's Guide: Springer; 2014.

Cheungpasitporn W, Thongprayoon $\mathrm{C}$, O'Corragain $\mathrm{O}$, Edmonds $\mathrm{P}$, Kittanamongkolchai W, Erickson S. Chronic Kidney Disease. Blood Purif. 2015;39:151-73.

Eknoyan G, Lameire N, Eckardt K, Kasiske B, Wheeler D, Levin A, et al. (2013). KDIGO 2012 clinical practice guideline for the evaluation and management of chronic kidney disease. Kidney Int. 2013;3:5-14.

Fokou M, Ashuntantang G, Teyang A, Kaze F, Mefire AC, Halle MP, et al. (2012). Patients characteristics and outcome of 518 arteriovenous fistulas for hemodialysis in a sub-Saharan African setting. Annals of vascular surgery. 2012;26(5):674-9.

Lazaniriana, R., et al. (2020). Formulation of Moringa oleifera Lam. based Bio-fortified Food Supplement for Pregnant Women in Madagascar, Indian Ocean Britain International of Exact Sciences (BIoEx) Journal Vol. 2 (2): 533-540.

Lilly MP, Lynch JR, Wish JB, Huff ED, Chen S-C, Armistead NC, et al. (2012). Prevalence of arteriovenous fistulas in incident hemodialysis patients: correlation with patient factors that may be associated with maturation failure. American Journal of Kidney Diseases. 2012;59(4):541-9.

Moon J-Y, Lee HM, Lee S-H, Lee T-W, Ihm C-G, Jo Y-I, et al. (2015). Hyperphosphatemia is associated with patency loss of arteriovenous fistula after 1 year of hemodialysis. Kidney Research and Clinical Practice. 2015;34(1):41-6.

Scholz H. AV Fistulas. (2015). Arteriovenous Access Surgery: Springer; 2015. p. 11-55.

Simorangkir, E. A., Pintauli, S., and Sudaryati, E. (2020). Relationship between Caries

Experience and Food Intake with Stunting Among 6-8-Years Old of Elementary School at Pantai Labu District in 2018. Britain International of Exact Sciences (BIoEx) Journal Vol. 2 (1):313-319.

Turner J.M., Bauer C., Abramowitz M.K., Melamed M.L., Hostetter T.H.. (2012). Treatment of chronic kidney disease. Kidney international. 2012;81(4):351-62. 